\title{
Long-term gene therapy with Dell fragment using nonviral vectors in mice with explanted tumors
}

\author{
This article was published in the following Dove Press journal: \\ OncoTargets and Therapy \\ 25 January 2016 \\ Number of times this article has been viewed
}

\author{
Hisataka Kitano' \\ Atsushi Mamiya' \\ Tomomi Ishikawa ${ }^{2}$ \\ Kayo Egoshi ${ }^{3}$ \\ Shinichiro Kokubun ${ }^{2}$ \\ Chiaki Hidai $^{2}$ \\ 'Division of Dental Surgery, School \\ of Medicine, Nihon University, \\ Tokyo, Japan; ${ }^{2}$ Division of Physiology, \\ Department of Biomedical Science, \\ School of Medicine, Nihon University, \\ Tokyo, Japan; ${ }^{3}$ School of Medicine, \\ Nihon University, Tokyo, Japan
}

\begin{abstract}
Cancer gene therapy using nonviral vectors is useful for long periods of treatment because such vectors are both safe and inexpensive, and thus can be used repeatedly. It has been reported that gene therapy with an $\mathrm{E} 3 \mathrm{C} 1$ fragment of Del1 in a mouse explanted tumor model improved prognosis. The present study aimed to analyze the long-term effects of repeated nonviral gene transfer of E3C1. Mice with explanted tumors of SCCKN cells, a human squamous carcinoma, were treated with a plasmid encoding E3C1. Plasmids were injected locally every week using a transfection reagent. Control mice treated with mock DNA started to be euthanized on day 18 , because the tumors had grown to over $15 \%$ of the body weight, and all of them had died by day 43. On the other hand, the tumors in two of ten mice treated with E3C1 had disappeared. The other eight mice started to be euthanized on day 46 and eight of ten mice had been euthanized by day 197. After 18 days of therapy, the tumor volume of control mice was $2,804 \pm 829 \mathrm{~mm}^{3}$ and that of the E3C1 mice was $197 \pm 159 \mathrm{~mm}^{3}$. Histochemical studies showed enhanced apoptosis in the E3C1-treated tumors, as compared with controls. Changes in cell morphology and decreased polymerized actin induced by $\mathrm{E} 3 \mathrm{C} 1$ indicated disturbed cell adhesion to the matrix. In in vitro studies of SCCKN cells, prolonged administration of an $\mathrm{E} 3 \mathrm{C} 1$ recombinant protein to cultured cells reduced adhesion-independent growth of cancer cells, as compared with control cells. These data suggest that $\mathrm{E} 3 \mathrm{C} 1$ treatment induces anoikis.
\end{abstract}

Keywords: cancer gene therapy, nonviral vector, apoptosis, anoikis, Del1

\section{Introduction}

At present, early cancers are treated with surgery, chemotherapy, and radiation therapy. However, these therapies have limited applications in advanced cancers such as metastatic cancers, and are associated with tolerance to therapy and dose limits. To improve the prognosis for advanced cancers that are unsuitable for conventional therapies, many efforts have been made for new technologies, including biotherapy where endogenous healing capacity is utilized. Alternatively, biotherapy is expected to support conventional therapy, regulating tolerances to chemotherapy and radiation therapy.

Gene therapy is a drug delivery technique for biotherapy. Currently, viral vectors are employed for most cancer gene therapies. Efficiency is often considered to be an advantage of viral vectors, whereas immunogenicity, pathogenicity, and carcinogenicity are considered disadvantages. ${ }^{1,2}$ There remains great hope that effective gene therapies based on nonviral vector delivery methods will be developed and used for gene therapy, as these methods have the potential to perform better than viral vectors in terms of both safety and cost efficiency. ${ }^{3,4}$ However, the gene transfer efficiency of nonviral vectors needs to be increased, and methods to cover the shortfall caused by the low efficiency of nonviral vectors are necessary.
Correspondence: Chiaki Hidai Division of Physiology, Department of Biomedical Science, School of Medicine, Nihon University, 30-I Oyaguchi-kami-cho, Itabashi-ku, Tokyo 162-8666, Japan

Tel +8I 33972 8I I I ext 2236

$\mathrm{Fax}+8 \mathrm{I} 339728292$

Email hidai.chiaki@nihon-u.ac.jp 
One of the simplest approaches to increasing the level of transgene expression is to perform repeated rounds of gene therapy. ${ }^{5-7}$ This approach is a realistic means to make use of the advantages of nonviral vectors, that is, safety and low cost. Nonviral vectors cannot realistically be used to introduce DNA into all cancer cells; thus, treatments with autonomously acting "suicide genes" such as p53 or thymidine kinase might not be suitable routes for development using nonviral vectors. ${ }^{8,9}$ Instead, methods that lead to the accumulation of expressed proteins in the extracellular matrix appear to be effective. ${ }^{10,11}$ Kitano et al ${ }^{10,11}$ have attempted gene therapy in mice with explanted tumors using a fragment of the Del1 protein, an extracellular matrix protein, and a nonviral vector. Del1 protein consists of five domains, including three epidermal growth factor repeats (referred to as E1, E2, and E3) and two discoidin domains (referred to as $\mathrm{C} 1$ and C2). ${ }^{12} \mathrm{E} 3$ has the ability to induce apoptosis and to increase gene transfer efficiency via induction of endocytosis. ${ }^{13,14} \mathrm{C} 1$ is essential for the deposition of Del1 in the extracellular matrix and could be used as a tool to deposit proteins into the extracellular matrix..$^{15}$ Therefore, it was expected that the E3C1 sequence of Del1 could deposit in the extracellular matrix in high concentration, induce apoptosis, and enhance the efficiency of subsequent transfections. In experiments by Kitano et al, ${ }^{10,11}$ DNA encoding a recombinant protein composed of $\mathrm{E} 3$ and $\mathrm{C} 1$ (referred to as $\mathrm{E} 3 \mathrm{C} 1$ ) in a nonviral vector was locally injected into mice with an explanted tumor every week. This protocol resulted in efficient deposition of $\mathrm{E} 3 \mathrm{C} 1$ into the tumor and in an increase in gene transfer efficiency. Fifty percent of the E3C1-treated mice survived for 7 weeks, whereas all of the control mice died.

The aim of the present study was to examine the effects of long-term treatment with E3C1. For this study, mice with an explanted tumor were consecutively treated with E3C1 until death. In vivo and in vitro experiments were then performed to investigate the mechanisms of the long-term curative effect of the $\mathrm{E} 3 \mathrm{C} 1$ treatments. This study suggests that the treatment deteriorates cell adhesion and increases sensitivity to anoikis.

\section{Materials and methods Cell lines and culture}

The human oral squamous cell carcinoma cell line SCCKN, a gift from Dr Hayashido (University of Hiroshima, Hiroshima, Japan), was grown in RD medium (45\% Dulbecco's Modified Eagle's Medium; Invitrogen, Carlsbad, CA, USA), 45\% RPMI 1640 medium (Invitrogen), and 10\% fetal bovine serum. ${ }^{16}$ Cells were cultured in $5 \% \mathrm{CO}_{2}$ at $37^{\circ} \mathrm{C}$. For all experiments that evaluated the effects of long-term E3C1 treatment, cells precultured with $1 \mathrm{pmol} / \mathrm{mL}$ of recombinant E3C1 for 10 days were employed.

\section{DNA constructs}

Mouse Del1 complementary DNA was a gift from Dr Quertermous (Stanford University, Stanford, CA, USA). To generate the plasmids used in the study, a fragment encoding the $\mathrm{E} 3$ and $\mathrm{C} 1$ sequence (E3C1, amino acids 122-316 of mouse Del1) was amplified using PCR with the forward primer 5'-TGTGAAGCTGAGCCTTGCAGAATGGCCGG A and the reverse primer 5'-ACAGCCTGAGAGCTCACAG CCAAGAAGTT. The signal peptide sequence of Dell and E3C1 complementary DNA were inserted into pcDNA3.1D (Invitrogen). Recombinant proteins expressed by the construct had V5-epitope tags at their C-terminal ends (Figure S1).

\section{Animal studies}

All animal experiments described in this study were carried out in accordance with both the Nihon University and the US National Institutes of Health animal care regulations. This study was approved by the ethics committee of Nihon university (AP13M045). Nu/Nu athymic nude mice were kept in a pathogen-free environment. For tumor explants, SCCKN cells were first seeded in $10 \mathrm{~cm}$ culture dishes overnight to reach $70 \%-80 \%$ confluence and were harvested using a cell stripper (Asone, Tokyo, Japan) after washing with phosphate-buffered saline (PBS). Cells were washed twice with PBS, centrifuged at $500 \times g$ for 5 minutes, and were then resuspended in RD medium at a concentration of $1 \times 10^{7} / 100 \mu \mathrm{L}$. A total of $100 \mu \mathrm{L}$ of suspended cells were injected subcutaneously into the right flank of a nude mouse (mock treatment, $\mathrm{n}=5 ; \mathrm{E} 3 \mathrm{C} 1$ treatment, $\mathrm{n}=10$ ). Animals were monitored twice weekly for tumor growth. When tumors were observed, their size was measured in two perpendicular dimensions using calipers. Tumor volume $\left(\mathrm{mm}^{3}\right)$ was calculated using the formula (width $\times$ length $^{2} / 2$ ). When tumor volume exceeded $60 \mathrm{~mm}^{3}$, treatment with plasmid encoding E3C1 (pE3C1) or pcDNA3, a mock vector, was initiated. For treatment, $10 \mu \mathrm{g}$ of DNA was injected into the tumor in $100 \mu \mathrm{L}$ increments using in vivo-jetPEI (Polyplus Transfection, San Marcos, CA, USA). Mice were euthanized when the tumors had grown to over $15 \%$ of the body weight. The observation period ended on day 197, when all mice treated with a mock plasmid had died. For histological experiments, after 4 weeks of treatment mice were sacrificed under deep anesthesia with isoflurane and the tumors were then harvested and $5 \mu \mathrm{m}$ frozen sections were prepared. 


\section{Reagents}

Recombinant fusion proteins with alkaline phosphatase (AP) were prepared as described previously. ${ }^{15,17}$ Briefly, an E3C1 fragment was generated using reverse transcription polymerase chain reaction and was cloned into an AP-tag4 vector (GenHunter, Nashville, TN, USA) for production of AP-tagged E3C1 as a secreted protein in Chinese Hamster Ovary cells cultured in 64 medium (60\% Opti-MEM and 40\% LHC-8 medium from Invitrogen). An AP tag without $\mathrm{E} 3 \mathrm{C} 1$ was used as a control. AP activity in conditioned medium was measured by adding $10 \mu \mathrm{L}$ of $0.05 \%$ Zwittergent (Calbiochem, La Jolla, CA, USA) in PBS to each well of a 96-well plate, followed by $20 \mu \mathrm{L}$ of conditioned medium. The plate was heated at $65^{\circ} \mathrm{C}$ for 30 minutes to inactivate endogenous AP. The enzyme reaction was initiated by adding $200 \mu \mathrm{L}$ of substrate $(1 \mathrm{mg} / \mathrm{mL}$ p-nitrophenyl phosphate (Sigma-Aldrich, St Louis, MO, USA) in $1 \mathrm{mM} \mathrm{MgCl}$ and $1 \mathrm{M}$ diethanolamine, $\mathrm{pH}$ 9.8) to each well, and the absorbance at $405 \mathrm{~nm}$ was measured after 30 minutes. Using the results with alkaline phosphatase purchased from Wako (Tokyo, Japan) as standard, the molarity of AP-tagged recombinant proteins was then calculated.

\section{Proliferation assay}

As treatment with $\mathrm{E} 3 \mathrm{C} 1$ affected cell adhesion, we observed cell numbers after cell adhesion culture. Control SCCKN cells and long-term $\mathrm{E} 3 \mathrm{C} 1$ treatment cells with $1 \mathrm{pmol} / \mathrm{mL}$ of recombinant $\mathrm{E} 3 \mathrm{C} 1$ were plated on 24 -well plates at $10 \%$ confluency, and were cultured in RD medium with or without AP-tagged E3C1 recombinant protein overnight, respectively. Cells were then harvested with trypsin/ethylenediaminetetraacetic acid and counted with a hemocytometer (day 0). After 24 hours, cells were counted again (day 1 ). The number of cells on day 0 was assigned a relative value of 1 .

\section{Immunohistochemistry}

Rabbit polyclonal antibodies against cleaved caspase-3 (Trevigen, Gaithersburg, MD, USA), Akt, phosphorylated Akt (Akt-Thr308, Akt-Ser473), and paxillin (Abcam) were purchased. Alexa Fluor 488- or Alexa Fluor 568-labeled goat antirabbit antibodies were purchased from Invitrogen. For immunohistochemistry, $5 \mu \mathrm{m}$ sections were fixed with $4 \%$ paraformaldehyde (PFA), incubated with primary antibodies, and then incubated with the appropriate secondary antibodies. Hoechst 33342 and Alexa Fluor 568-labeled phalloidin were used to visualize nuclei and polymerized actin, respectively. An Axioscope 2 (Carl Zeiss Microimaging Inc., Welwyn Garden City, UK) equipped with an AxioCam (Carl Zeiss) was used to observe tissues and take photographs.

\section{Analysis of apoptosis in pileup culture}

Cells were cultured on glass bottom dishes coated with fibronectin for 10 days. At this point, the cells exceeded confluency, which allowed control cells to pileup. Cells were fixed with 4\% PFA and stained as described earlier. A confocal microscope, TCS-SP5 (Leica, Wetzlar, Germany) was used to take photographs and to reconstitute vertical cross-sectional views.

\section{Wound healing assay}

Cells were plated at a dilution consistent with confluence in a $5 \mathrm{~mm}$ diameter plastic ring on a plastic tissue culture dish coated with fibronectin. After 6 hours, the ring was removed and cell migration was initiated with $1 \mathrm{pmol} / \mathrm{mL}$ of AP or AP-tagged E3C1. Cells were observed by timelapse microscopy using a Cellwatcher (Corefront, Tokyo, Japan) in 64 medium at $37^{\circ} \mathrm{C}$. The average velocity of migration was estimated by measuring the increase in the area of cell coverage after 2 hours using PopImaging Time Lapse Tracer software (Digital Being Kids, Kanagawa, Japan). After 24 hours of migration, cells were fixed with $4 \%$ PFA and stained with trypan blue. All experiments were repeated three times. Data were reported as mean \pm standard deviation.

\section{Three-dimensional migration assay}

A cell suspension was made in a collagen solution (Koken, Tokyo, Japan) on ice and was incubated for 1 hour in an incubator so that the solution turned into a gel. Fresh medium containing $1 \mathrm{pmol} / \mathrm{mL}$ of AP or AP-tagged $\mathrm{E} 3 \mathrm{C} 1$ was then added and cell migration was observed using time-lapse microscopy and a Cellwatcher (Corefront). Migration distances from the gravity center were measured every minute and were summated for 2 hours.

\section{Western blot}

Cells were cultured in $3.5 \mathrm{~cm}$ diameter dishes and cultured overnight. Subsequently, $1 \mathrm{pmol} / \mathrm{mL}$ AP or AP-tagged E3C1 was added every day and cells were harvested on the indicated day with sample buffer. Samples were separated by sodium dodecyl sulfate-polyacrylamide gel electrophoresis and transferred to a polyvinylidene difluoride membrane (ATTO, Tokyo, Japan). Membranes were incubated with primary antibodies, followed by horseradish peroxidase-conjugated secondary antibodies, and immunoreactive proteins were detected using the ECL Advance Western Blotting Detection Kit (Amersham, Piscataway, NJ, USA). 


\section{Statistical analysis}

Results are expressed as mean \pm standard deviation. Wilcoxon rank sum test was performed as appropriate, and statistical significance was defined as $P<0.05$.

\section{Results}

In order to analyze the effects of long-term treatment with E3C1, mice were injected with a DNA complex of mock DNA or of pE3C1 once a week. All of the 15 mice (mock treatment, $\mathrm{n}=5 ; \mathrm{E} 3 \mathrm{C} 1$ treatment, $\mathrm{n}=10$ ) were euthanized because the tumors had grown to over $15 \%$ of the body weight. Control mice treated with mock DNA started to be euthanized on day 18 and all of them had died by day 43 (Figure 1A). On the other hand, the E3C1-treated mice started to be euthanized on day 36 and 8 of 10 mice had been euthanized by day 197. As the tumors in the other two mice had disappeared by day 197, observation of the mice was then concluded. After 18 days of therapy, the tumor volume of control mice was $2,804 \pm 829 \mathrm{~mm}^{3}$ and that of the
E3C1 mice was $197 \pm 159 \mathrm{~mm}^{3}$ (Figure 1B). Treatment with $\mathrm{E} 3 \mathrm{C} 1$ significantly suppressed the increase in tumor volume. In control mice, the tumor volume suddenly increased around day 30 and then continuously increased until death (Figure 1C). The time courses of the tumor growth of treated mice were distinct from those of control mice (Figure 1D). Most tumors treated with E3C1 grew much more slowly than control tumors.

Kitano et $\mathrm{al}^{11}$ reported that the first injection of $\mathrm{pE} 3 \mathrm{C} 1$ induced apoptosis in explanted tumors. To examine whether consecutive injections of $\mathrm{pE} 3 \mathrm{C} 1$ maintained these apoptotic effects on tumor cells, apoptosis of control- and E3C1-treated tumors was examined after 4 weeks of treatments (Figure 2A). Immunohistochemical analysis using an anticleaved caspase- 3 antibody indicated apoptosis in the necrotic focus and the border regions of the necrotic focus and parenchyma in E3C1-treated tumors. In contrast, only a few apoptotic cells were observed in control tumors. To evaluate the long-term effects of E3C1 on tumor cells,
A
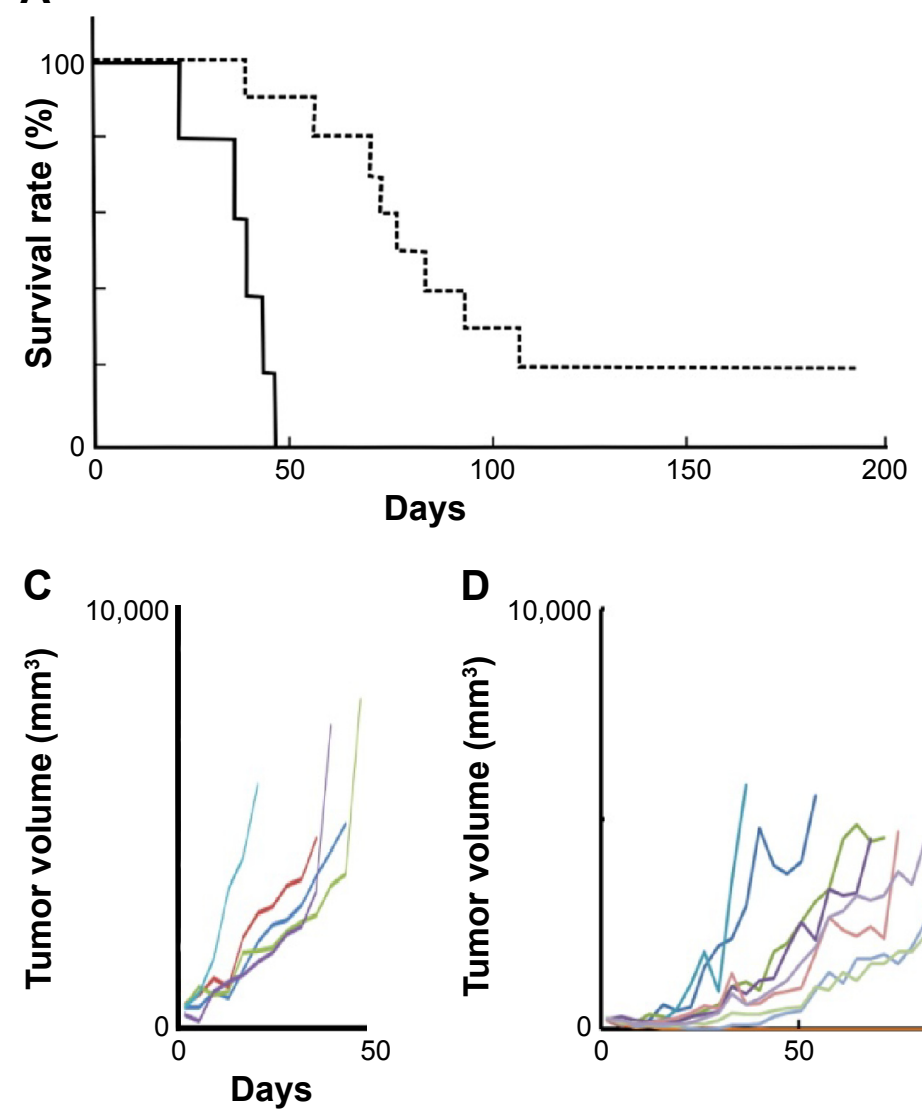

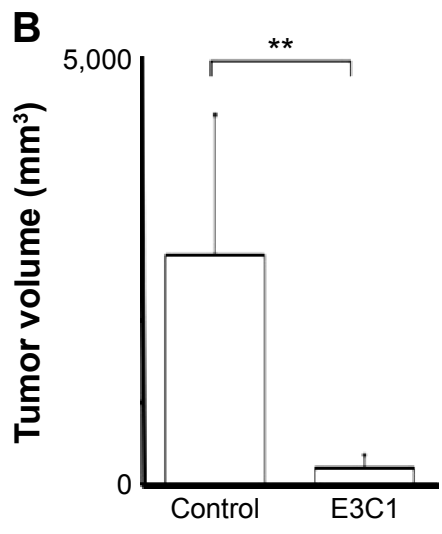

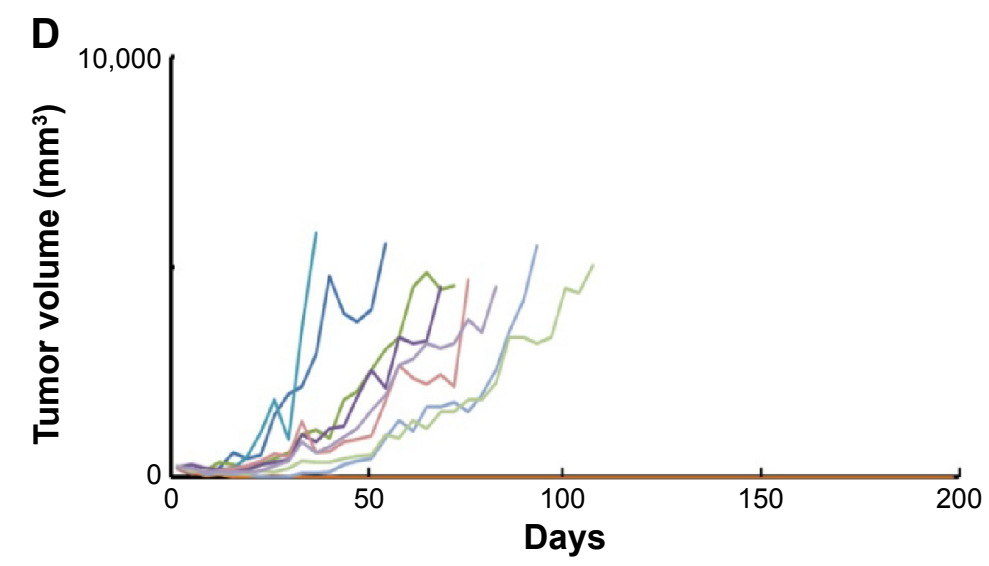

Figure I Treatment with $\mathrm{pE} 3 \mathrm{Cl}$ improved the prognosis of model mice.

Notes: (A) Kaplan-Meier survival curves of mice with tumors treated with mock vector (solid line) or with $\mathrm{pE} 3 \mathrm{Cl}$ (dashed line). Survival rate for $\mathrm{pE} 3 \mathrm{Cl}$-treated mice was significantly higher than that for mock vector-treated mice $(P<0.05)$. (B) Comparison of tumor volume after 18 days of treatment. Results were expressed as mean \pm standard deviation. $* * P<0.01$. Chronological changes in tumor volume in individual mice following mock treatment $(\mathbf{C})$ and $\mathrm{E} 3 \mathrm{Cl}$ treatment $(\mathbf{D})$.

Abbreviation: $\mathrm{pE} 3 \mathrm{Cl}$, plasmid encoding $\mathrm{E} 3 \mathrm{Cl}$. 

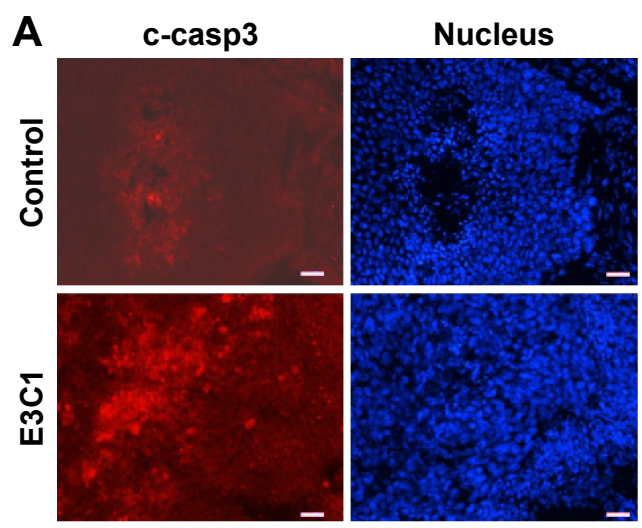

C
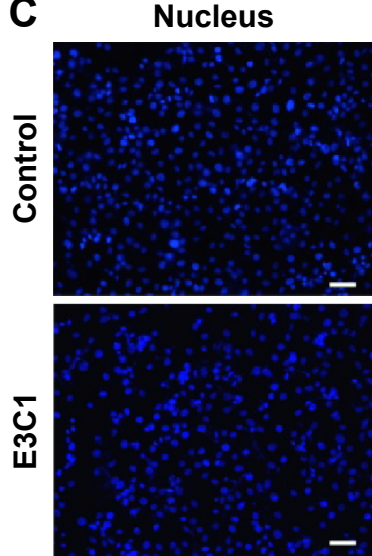

Nucleus
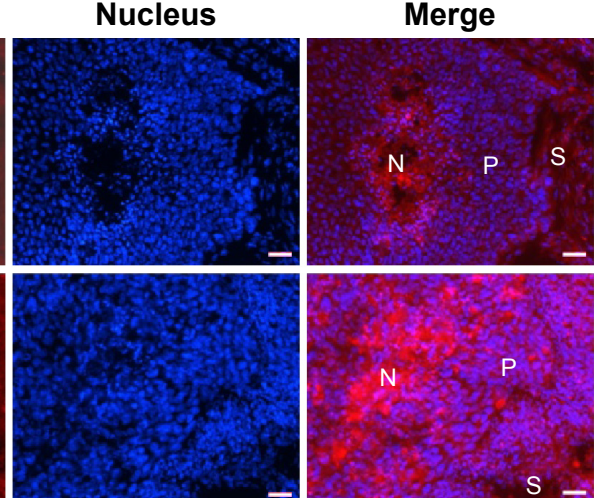

c-casp3

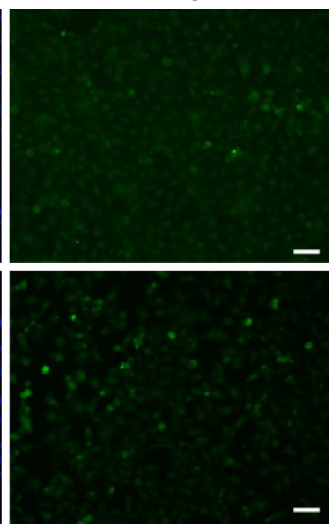

B

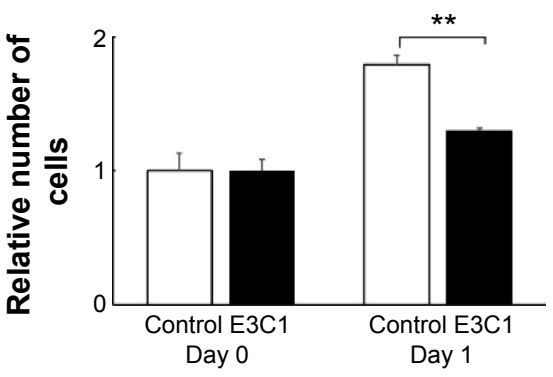

D

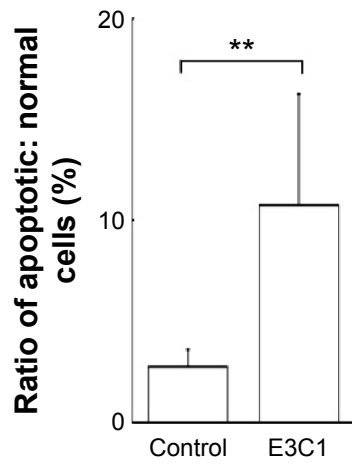

Figure 2 Consecutive treatments with $\mathrm{E} 3 \mathrm{Cl}$ induced apoptosis in vivo and in vitro.

Notes: (A) Representative images of distribution of apoptotic cells in tumors of mice on day 28 of control or E3Cl treatment. Apoptosis was examined with anticleaved caspase-3 (c-casp3) antibody and nuclear staining with Hoechst 33342. (B) Growth of SCCKN cells in vitro in the presence or absence of E3CI. Number of cells on day 0 was assigned a value of I. (C) Apoptotic cells in SCCKN cells detected with a c-casp3 antibody. Hoechst 33342 was used for counterstaining of the nuclei in vitro. Scale bars in $\mathbf{A}$ and $\mathbf{C}$ correspond to $50 \mu \mathrm{m}$. (D) Graph shows the ratio of apoptotic cells to the total cell number in each cell population. Results are expressed as mean \pm standard deviation. $* * P<0.01$.

Abbreviations: $\mathrm{N}$, necrotic lesion; $\mathrm{P}$, parenchyma; S, stroma.

in vitro experiments using cells of the human oral squamous cell carcinoma cell line SCCKN, which were cultured with a recombinant AP-tagged $\mathrm{E} 3 \mathrm{C} 1$ protein, were conducted. The proliferation of these cells was suppressed in the continuous presence of the recombinant E3C1 protein (Figure 2B). Thus, the number of cells treated with control protein (the AP-tag alone) increased 1.82 \pm 0.07 times over 24 hours, whereas the number of cells treated with the recombinant E3C1 protein increased $1.31 \pm 0.02$ times over 24 hours. Immunohistochemical analysis of these cells using the anticleaved caspase-3 antibody indicated increased apoptosis in the culture treated with the recombinant $\mathrm{E} 3 \mathrm{C} 1$ protein, as compared with control cells (Figure 2C and D). Thus, $2.7 \% \pm 0.9 \%$ of the cells treated with the control protein were positive for cleaved caspase-3, whereas $10.8 \% \pm 0.6 \%$ of cells treated with the recombinant $\mathrm{E} 3 \mathrm{C} 1$ protein were positive for cleaved caspase-3. Detection of apoptotic cells based on the presence of phosphatidylserine using polarity-sensitive indicator for viability and apoptosis provided further proof that cells underwent higher apoptosis following treatment with the $\mathrm{E} 3 \mathrm{C} 1$ protein than with the control protein (Figure S2). These data suggested that long-term E3C1 treatment affects the growth of cancer cells.

In order to evaluate the effects of $\mathrm{E} 3 \mathrm{C} 1$ on the sensitivity of cells to deadhesion from the matrix, the effects of E3C1 on the piling up of cells in two-dimensional (2D) culture was examined. Immunohistochemical analysis of these cells with the anticleaved caspase-3 antibody showed increased apoptosis in cells that were cultured long-term with the recombinant $\mathrm{E} 3 \mathrm{C} 1$ protein, as compared with controls (Figure 3A). These cells were further analyzed by confocal microscopy. Analysis showed that the cells in the control culture grew and piled up to two or three cell layers (Figure 3B). Apoptotic cells were distributed randomly in these control cultures. On the other hand, cells treated with recombinant E3C1 protein generally could not pile up. In addition, most of the apoptotic cells in E3C1-treated cultures appeared to be detached from the bottom of the dish (Figure 3B). These 
A

c-casp3
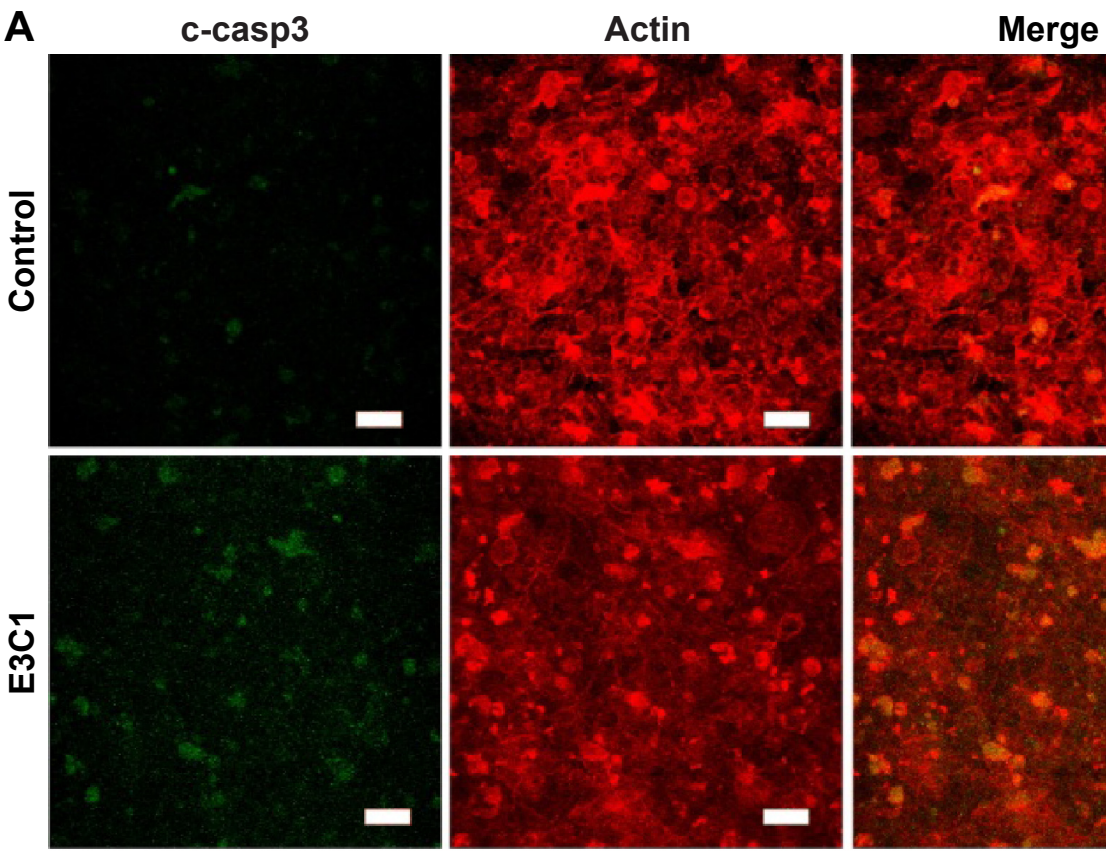

B

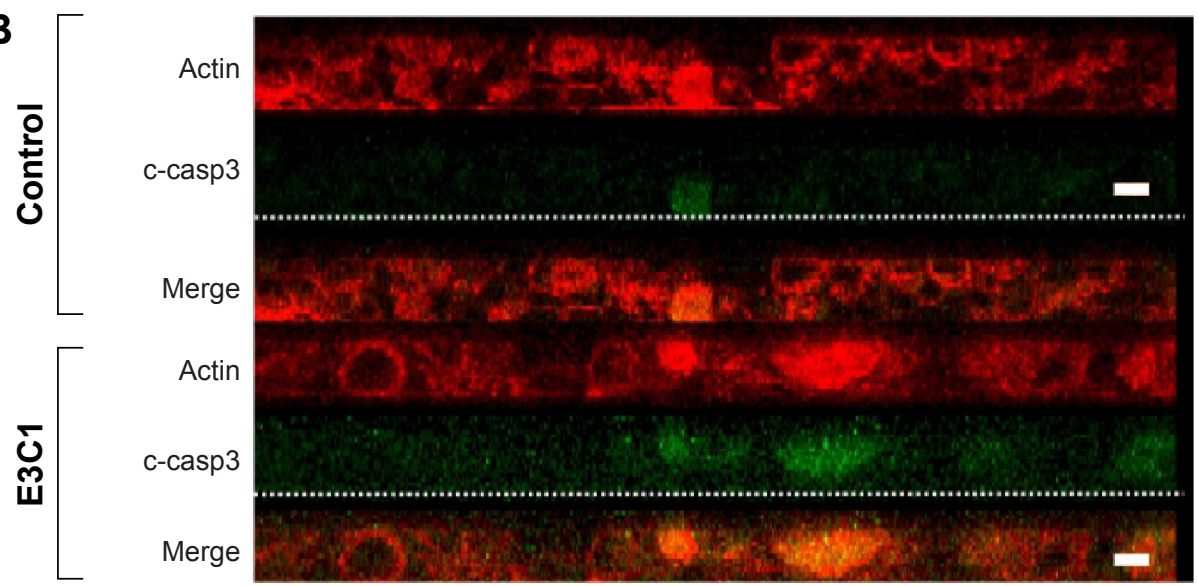

Figure 3 Consecutive culture with recombinant $\mathrm{E3Cl}$ induced apoptosis in cells without adhesion to the matrix.

Notes: (A) Apoptotic cells within SCCKN cell populations treated with or without E3CI were detected with anticleaved caspase-3 (c-casp3) antibody and Alexa Fluor 568 conjugated phalloidin (which stains actin). (B) Reconstituted vertical cross-sectional views of the cells in part $\mathbf{A}$. Dotted lines indicate the bottoms of cover glass. Scale bars in $\mathbf{A}$ and $\mathbf{B}$ correspond to 50 and $10 \mu \mathrm{m}$, respectively.

data suggest that E3C1 enhanced the sensitivity of the cells to deadhesion from the cell matrix.

Tumors from mice treated for 4 weeks were examined by hematoxylin and eosin staining (Figure 4). Tumors from both mock-treated and E3C1-treated mice were composed of parenchyma, necrotic lesions in the parenchyma, and stroma. Control tumors displayed many protrusions into the surrounding tissue, suggesting tumor invasiveness. In contrast, E3C1-treated tumors displayed a smooth surface. When compared with mock mice, the stroma in the E3C1-treated mice showed much more finely segmented parenchyma.

Because suppression of the growth of tumor protrusions by $\mathrm{E} 3 \mathrm{C} 1$ treatment was observed by hematoxylin and eosin staining, the effects of $\mathrm{E} 3 \mathrm{C} 1$ on cell migration were investigated in vitro (Figure 5A and B). In a wound healing assay, the cell scattering observed in control cells was suppressed by $\mathrm{E} 3 \mathrm{C} 1$ treatment. Cells in control culture migrated at a rate of $100 \pm 29 \mu \mathrm{m} / \mathrm{h}$, whereas cells in the culture treated with the recombinant $\mathrm{E} 3 \mathrm{C} 1$ protein migrated at a rate of $65 \pm 13 \mu \mathrm{m} / \mathrm{h}$. We next examined the effects of E3C1 treatment on cell migration in three-dimensional (3D) culture (Supplementary $\underline{\text { videos } \mathrm{S} 1}$ and $\underline{\mathrm{S} 2}$ ). The distance covered by random migration in a collagen gel by control and E3C1-treated cells was $4.5 \pm 2.9 \mu \mathrm{m} / \mathrm{h}$ and $1.9 \pm 1.2 \mu \mathrm{m} / \mathrm{h}(P=0.0084)$, respectively (Figure $5 \mathrm{C}$ ). Cells treated with control protein assumed a spindle shape in 3D culture (Figure 5D). On the other hand, 

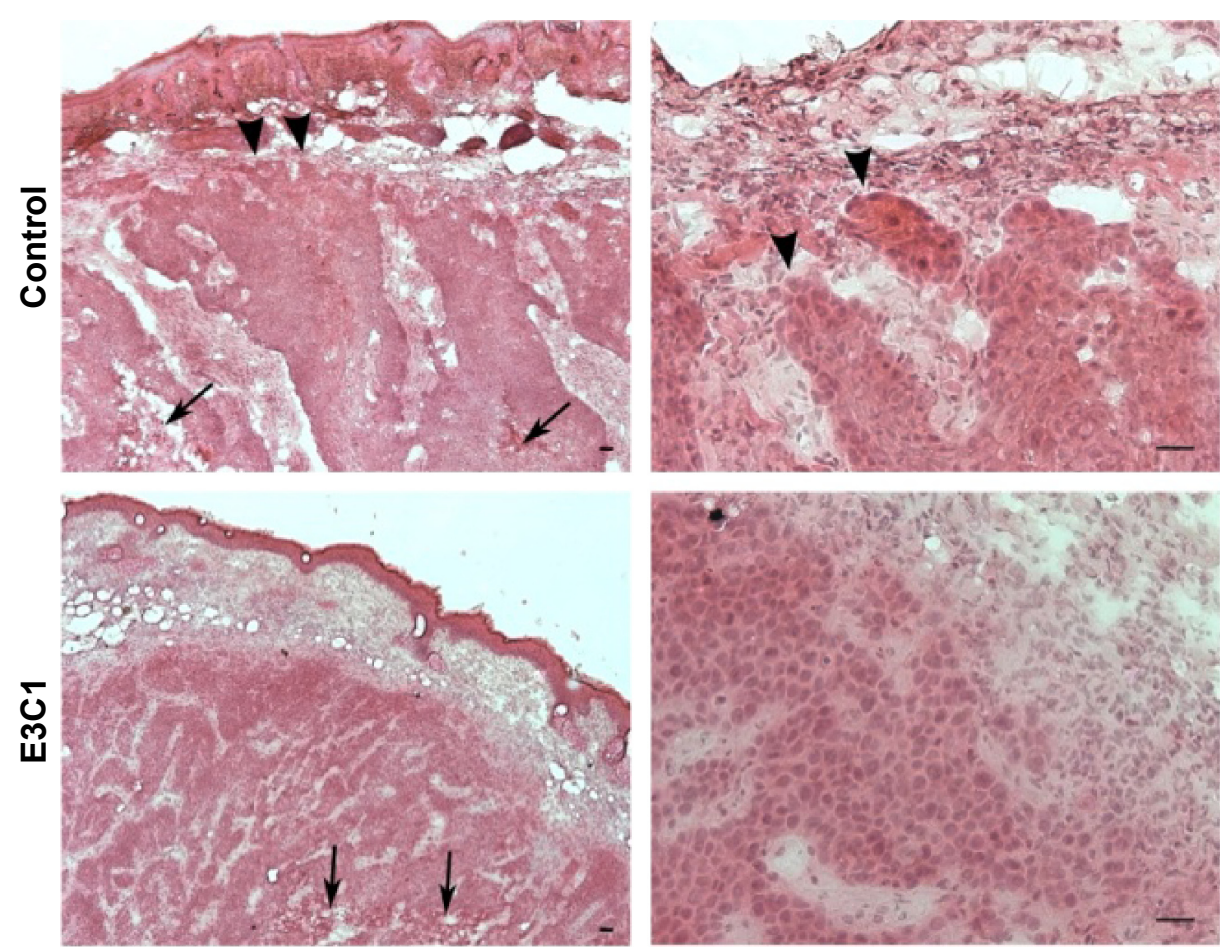

Figure 4 Hematoxylin and eosin staining of representative explanted tumors on day 28. Notes: Images on the left were taken by $\times 5$ objective lens; images on the right were taken by $\times 20$ objective lens. Arrows indicate necrotic lesions. Arrowheads indicate invasive protrusions of tumor in mock-treated mouse. Scale bars correspond to $50 \mu \mathrm{m}$.

cells treated with $\mathrm{E} 3 \mathrm{C} 1$ protein assumed a circular shape with poorly developed protrusions. These morphological changes suggested that $\mathrm{E} 3 \mathrm{C} 1$ suppressed cell adhesion to the matrix.

In order to evaluate cell shape and adhesion in 3D culture, cells were observed under confocal microscopy. In this analysis, control cells had a spindle shape and a long ellipsoidal nucleus. On the other hand, E3C1-treated cells had poorly developed protrusions and faint staining of polymerized actin (Figure 6A). Because there was strong suppression of actin polymerization by $\mathrm{E} 3 \mathrm{C} 1$ in $3 \mathrm{D}$ cultured cells, the phalloidin staining pattern of tumors was also investigated (Figure 6B). Polymerized actin in the control tumor showed diffuse staining and that in the $\mathrm{E} 3 \mathrm{C} 1$-treated tumor was detected only at the peripheral region of the cells, resulting in a mesh-like appearance. Changes in actin polymerization with $\mathrm{E} 3 \mathrm{C} 1$ treatment suggested a change in cell adhesion in vivo. To confirm the effects of $\mathrm{E} 3 \mathrm{C} 1$ on cell adhesion, immunohistochemistry for adhesion molecules was performed. Cultured SCCKN cells on fibronectin-coated cover glass were treated with $1 \mathrm{pmol} / \mathrm{mL}$ of an $\mathrm{E} 3 \mathrm{C} 1 \mathrm{recom}-$ binant protein for 10 minutes and were stained for paxillin and actin (Figure 6C). In control cells, paxillin and actin were stained in circular shapes corresponding to the cell edge and at filopodia. On the other hand, circular patterns were disturbed in E3C1-treated cells. Treatment with E3C1 quickly changed the adhesion state of SCCKN cells in 2D culture.

E3C1 treatment induced apoptosis with disturbance of adhesion. These results suggest that the apoptosis induced by $\mathrm{E} 3 \mathrm{C} 1$ was anoikis. As SCCKN cells are originally resistant to deadhesion (Figure 3), it was speculated that signals to change the susceptibility to anoikis were induced by $\mathrm{E} 3 \mathrm{C} 1$. The serine threonine kinase Akt1 is essential for the regulation of important cellular functions such as cell survival and cell growth. ${ }^{18,19}$ As activation of Akt signaling pathway is the most common mechanism to achieve anoikis resistance in cancer cells, phosphorylation of Akt was analyzed (Figure 7A). Western blot of tumor tissue, using an antibody against Akt phosphorylated at Thr308, showed that the level of phosphorylation decreased gradually over 8 days after administration of the recombinant $\mathrm{E} 3 \mathrm{C} 1$ protein. On the other hand, Akt phosphorylation at Ser473 did not change at all.

We next examined the expression pattern of Akt phosphorylated at Thr308 or at Ser473 in tumors using immunohistochemistry. In control tumors, Akt phosphorylated at Thr308 was localized in the cytoplasm of cells at the periphery of the parenchyma (Figure 7B). In E3C1-treated tumors, staining of Akt phosphorylated at Thr308 was diminished when compared with controls. On the other hand, in cells of 
A
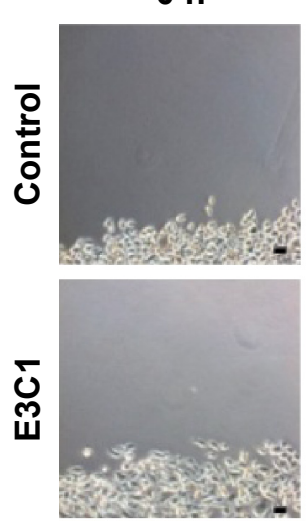

C

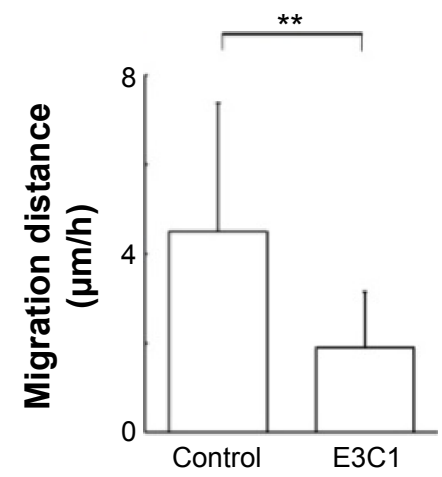

B

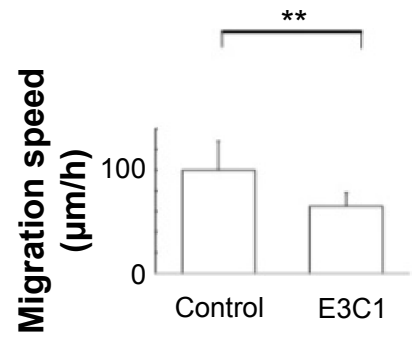

D

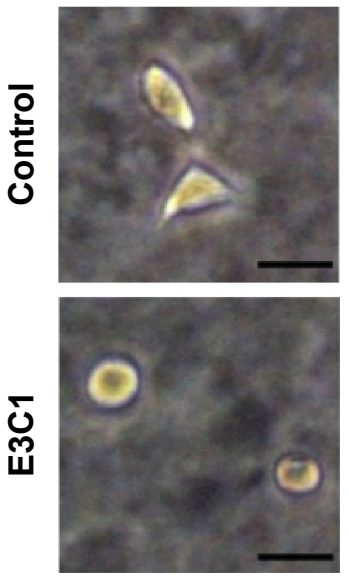

Figure 5 Consecutive treatment with recombinant $\mathrm{E} 3 \mathrm{Cl}$ suppressed cell migration in vitro.

Notes: (A) Phase-contrast images of wound healing assay of SCCKN cells consecutively treated with recombinant E3CI or control. (B) Graph shows migration velocity of control and E3CI cells. (C) Graph shows migration distance of cells in collagen gel. (D) Phase-contrast photographs of control and E3Cl-treated SCCKN cells in 3D culture. Scale bars correspond to $50 \mu \mathrm{m}$. Results are expressed as mean \pm standard deviation. $* * p<0.01 ; n=20$.

Abbreviations: 3D, three-dimensional; h, hours.

control tumors, Akt phosphorylated at Ser473 was diffusely distributed throughout the entire cell (Figure 7C), whereas in E3C1-treated tumors, it was restricted to the peripheral area of the cells in the parenchyma and stroma.

\section{Discussion}

A number of molecules have been developed as agents for cancer treatment. Unfortunately, many of these have become ineffective due to tolerance or have failed to produce satisfactory results. Thus, treatment with $\mathrm{E} 3 \mathrm{C} 1$ was expected to be effective after long therapy, as it a biological molecule. This study showed that gene therapy with E3C1 using a nonviral vector was effective over a long period. The growth ratio of E3C1-treated tumors was lower when compared with control tumors at the end of observation. This treatment controlled tumor size for 3 months. In addition to tumor growth, tumor invasiveness was considered to be suppressed. The effects of E3C1 treatment should significantly extend survival times.
Apoptosis of tumor cells induced by E3C1 treatment contributed to the inhibitory action of $\mathrm{E} 3 \mathrm{C} 1$ on tumor growth. In this study, most of the apoptosis was detected in the necrotic focus. The reason for this localization of apoptosis may be due to the fact that although E3C1 could not induce apoptosis alone, it has been reported that a recombinant E3 protein can only induce apoptosis in $30 \%$ of treated cells in vitro. ${ }^{20}$ Some conditions given in vivo could increase the capacity of $\mathrm{E} 3 \mathrm{C} 1$ to induce apoptosis. E3C1 induction of apoptosis might be helped by the hypoxic conditions in the necrotic focus.

Anoikis is a programmed cell death induced by cell deadhesion from extracellular matrix. ${ }^{21}$ Apoptosis induced by $\mathrm{E} 3 \mathrm{C} 1$ treatment is accompanied by deterioration of cell adhesion. Our experiment showed that E3C1 attenuated formation of focal complexes in vitro. Distribution of polymerized actin was disturbed by $\mathrm{E} 3 \mathrm{C} 1$ treatment in vitro and in vivo. In 3D culture, protrusions of cells treated with E3C1 were poorly developed. These data suggest the attenuation 
A

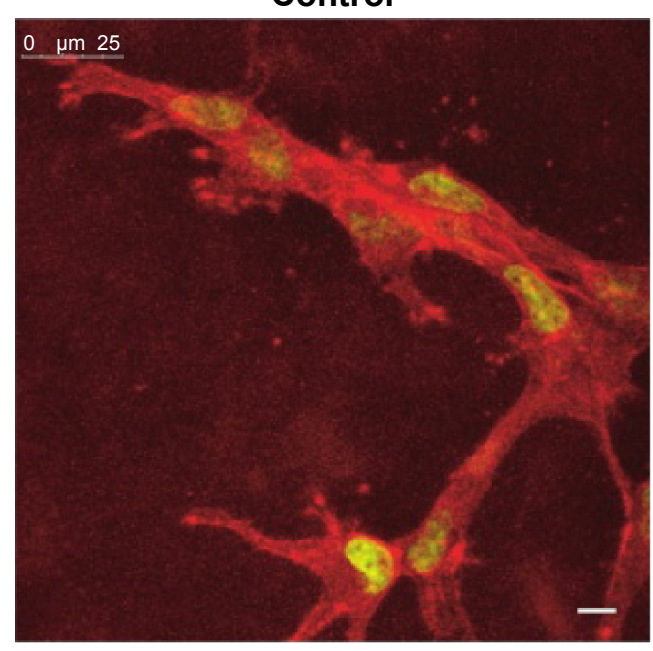

B
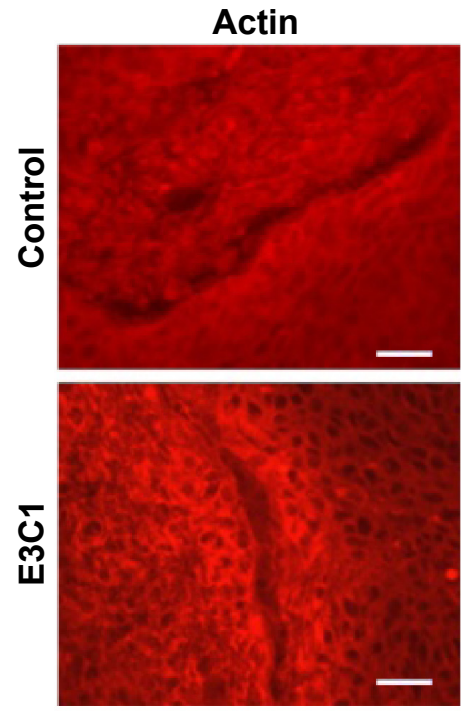

C
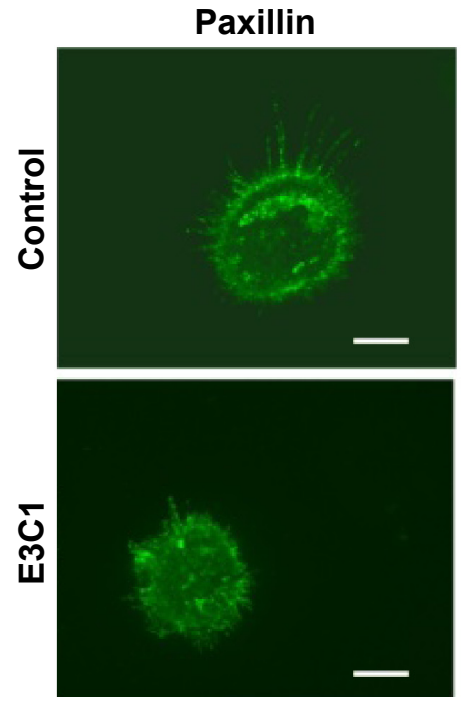

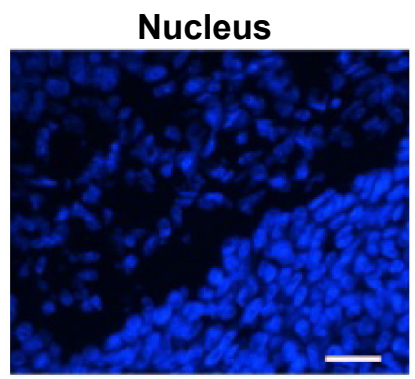

E3C1

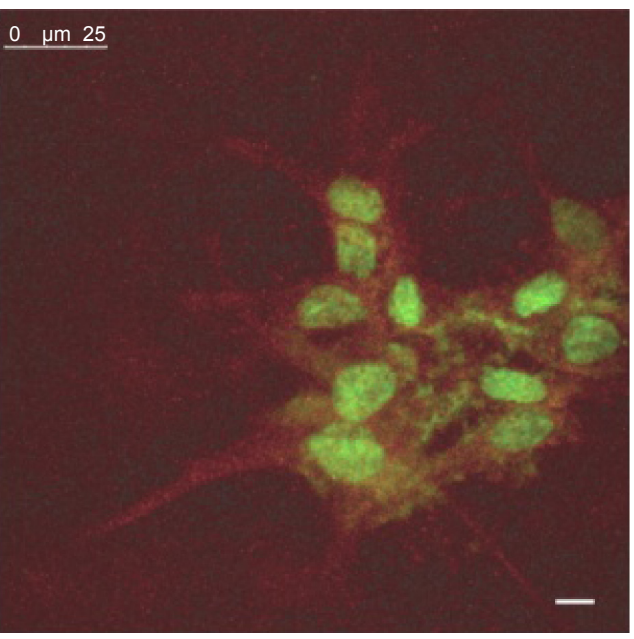

Merge
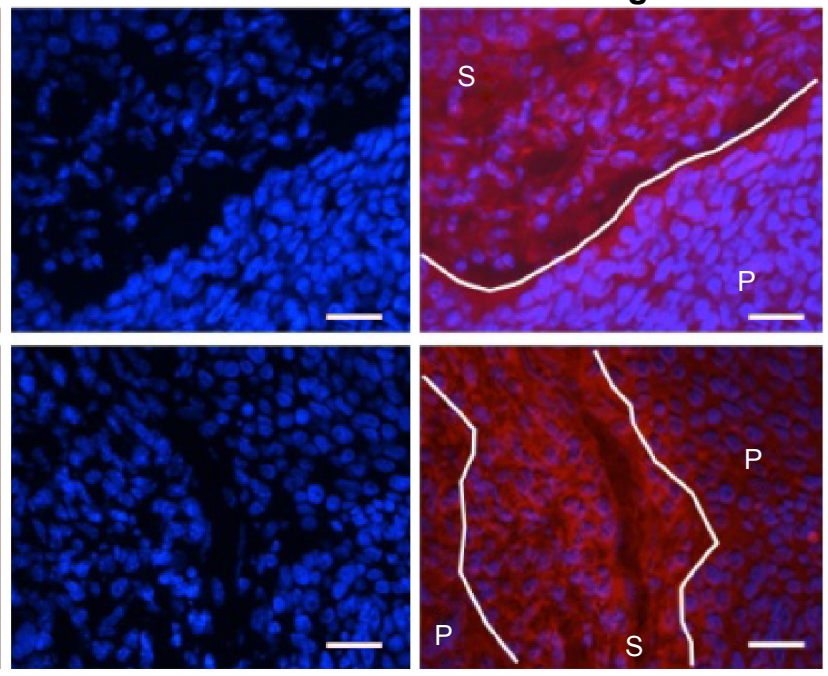

Actin
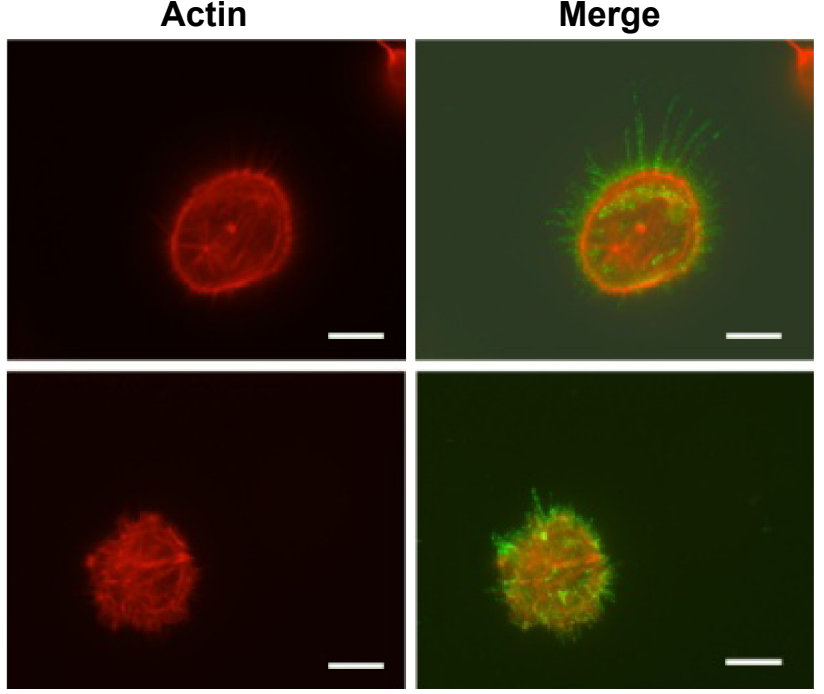

Figure 6 Polymerized actin distribution with recombinant $\mathrm{E} 3 \mathrm{CI}$.

Notes: (A) Cells grown in collagen gel with control protein or recombinant E3CI were stained for actin with phalloidin (red) and for nuclei with SYTOX (green). Scale bar corresponds to $10 \mu \mathrm{m}$. (B) Polymerized actin stained with Alexa Fluor 568-labeled phalloidin (red) in tumor cells repeatedly treated with mock vector (control) or pE3Cl $(\mathrm{E} 3 \mathrm{CI})$. Nuclei were stained with Hoechst 33342. Scale bar corresponds to $50 \mu \mathrm{m}$. (C) Immunohistochemistry for paxillin (green). Actin was stained with Alexa Fluor $568-$ labeled phalloidin (red). Scale bars correspond to $10 \mu \mathrm{m}$.

Abbreviations: $\mathrm{pE} 3 \mathrm{Cl}$, plasmid encoding $\mathrm{E} 3 \mathrm{Cl}$; $\mathrm{P}$, parenchyma; $\mathrm{S}$, stroma. 
A

Control p-Akt-Thr308 $\left[\begin{array}{c}\text { p-Akt-Thr308 } \\ \text { p-Akt-Ser473 }\end{array}\right.$

E3C1

B
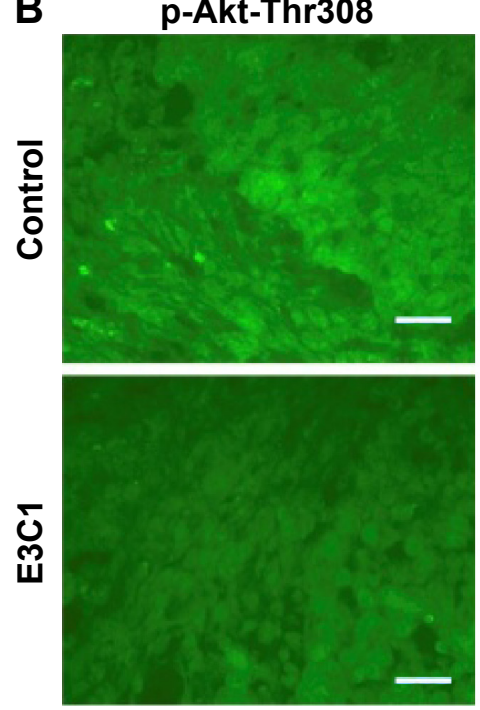

C
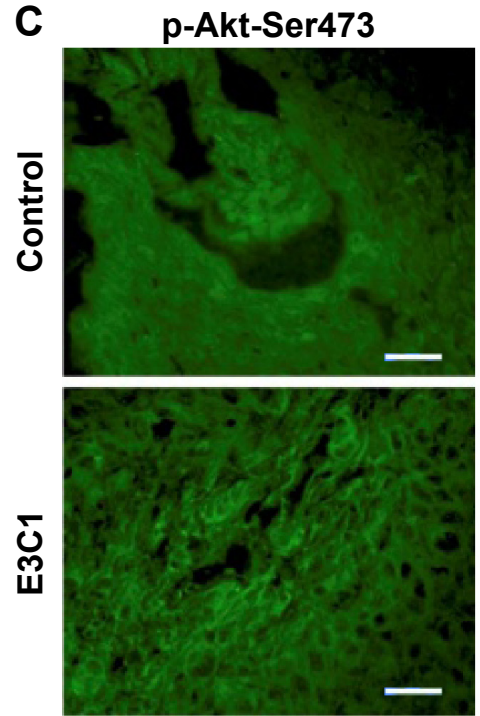

$\beta$-Actin

\section{Days}

$\begin{array}{lll}0 & 1 & 2\end{array}$

4

6

8

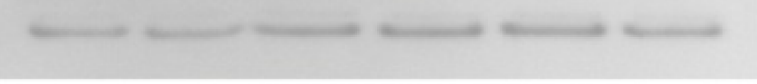

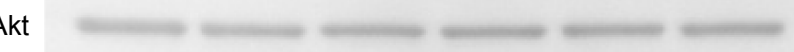
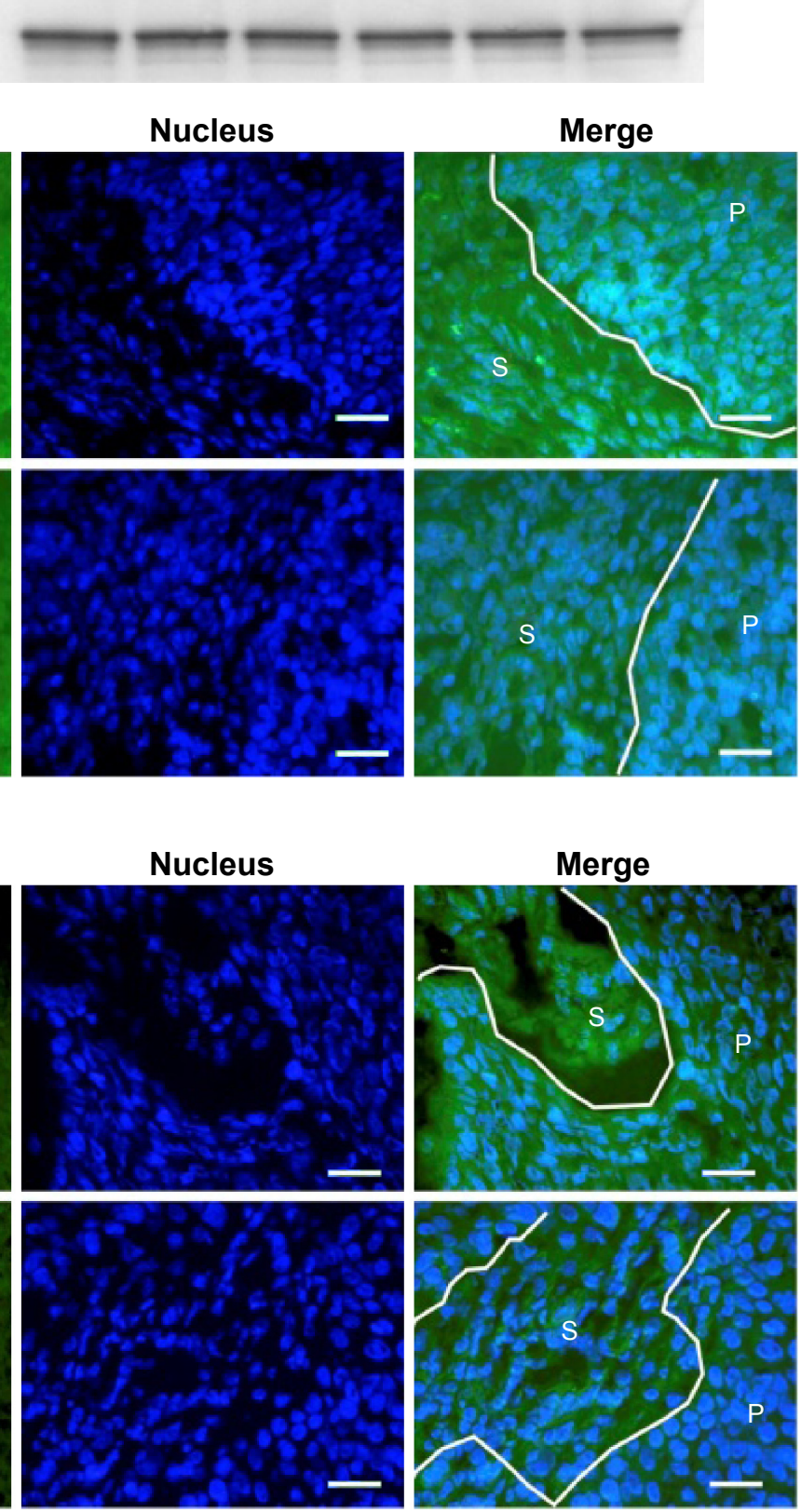

Figure 7 Phosphorylation of proteins involved in Akt signaling.

Notes: Protein expression was examined with antibody against Akt phosphorylated at Thr308 (p-Akt-Thr308) or at Ser473 (p-Akt-Ser473). (A) Western blots of proteins in $\mathrm{E} 3 \mathrm{Cl}$-treated and control cells involved in Akt signaling. Immunohistochemical analyses of control or E3Cl-treated mouse tumor for $\mathrm{p}$-Akt-Thr308 (B) and p-Akt-Ser473 (C). Lines indicate borders between stroma and parencyhma. Scale bars correspond to $50 \mu \mathrm{m}$.

Abbreviations: $\mathrm{P}$, parenchyma; $\mathrm{S}$, stroma. 
of cell adhesion to the substrate. The effects of E3C1 on cell adhesion could be related to the function of Del1. Del1 has an Arg-Gly-Asp sequence in the second EGF domain (E2) that is involved in cell adhesion via integrins. ${ }^{22}$ On the other hand, it has been reported that Del1 suppresses binding between leucocytes and endothelial cells in inflammation. ${ }^{23}$ It is possible that E3 is an anti-adhesion domain and that Del1 functions in an adhesive or anti-adhesive manner according to circumstances. In addition, Arg-Gly-Asp participates in cell survival signals and $\mathrm{E} 3$ has been reported to induce apoptosis. Isolation of the $\mathrm{E} 3 \mathrm{C} 1$ fragment from Del1 may enhance $\mathrm{E} 3 \mathrm{C} 1$ activity to attenuate cell adhesion and induce cell death.

In addition to disorder of cell adhesion, treatment with $\mathrm{E} 3 \mathrm{C} 1$ increases the susceptibility of tumor cells to anoikis. SCCKN cells are tolerant to anoikis and can generally pileup in $2 \mathrm{D}$ culture. However, treatment with E3C1 caused the loss of pileup activity. This suggests that $\mathrm{E} 3 \mathrm{C} 1$ increases the susceptibility of the cells to anoikis. Susceptibility to anoikis is regulated by many factors. In this study, Akt signaling was investigated as an anoikis-regulating factor. Akt1 is a general protein kinase that activates signals downstream of phosphatidylinositol 3 kinase to mediate the effects of various growth factors. The activity of Akt1 is involved in the metastasis, invasion, and prognosis of several carcinomas. ${ }^{18}$ The activation of Akt1 induces anoikis resistance. ${ }^{24,25}$ And molecules that inhibit these signals and increase sensitivity to anoikis can be utilized for cancer therapy. ${ }^{26,27}$ In the present study, the phosphorylation and cellular distribution of Akt1 was changed by E3C1. Although the phosphorylation of Akt at Ser473 was stable, the phosphorylation of Akt at Thr308 was suppressed by continuous administration of $\mathrm{E} 3 \mathrm{C} 1$ to cells in vitro, while the cellular distribution of Akt phosphorylated at Ser473 changed with E3C1 treatment in vivo. Phosphorylation of Akt on both Thr308 and Ser473 is required for full activity of Akt 1 and these phosphorylations are independently regulated. Akt is phosphorylated at the plasma membrane, where it is targeted by phosphoinositidedependent kinase 1 and mammalian target of rapamycin complex 2 for phosphorylation on Thr308 and Ser473, respectively. ${ }^{28}$ It has been reported that phosphorylation of Akt on Thr308 is involved in cell proliferation and survival. ${ }^{29}$ Akt phosphorylation on Ser473 does not necessarily mean high malignancy in cancer cells. ${ }^{30}$ It has been reported that Akt1 phosphorylated at Ser473, but not at Thr308, does not move into the nucleus. ${ }^{31}$ In the present study, Akt that was phosphorylated at Ser473 was not detected in the central region of cells in tumors treated with $\mathrm{E} 3 \mathrm{C} 1$. It is thus possible that $\mathrm{E} 3 \mathrm{C} 1$ treatment regulates nuclear distribution of Akt. Phosphorylation and distribution of Akt could be related to the induction of anoikis by $\mathrm{E} 3 \mathrm{C} 1$.

Histological and in vitro analyses suggested that E3C1 treatment suppressed cell invasiveness. Hematoxylin and eosin staining of explanted tumors indicated that the surface shape of tumors was changed by E3C1 treatment. Thus, the tumor surface was smooth in E3C1-treated mice in contrast to the ragged surface with budding that was present in control tumors. Because budding is a sign of malignant pathology, the disappearance of budding is considered to be a benign change, suggesting low invasiveness. In in vitro experiments, long-term exposure to $\mathrm{E} 3 \mathrm{C} 1$ caused a decrease in the migration of cells. Low motility could be explained by disruption of adhesion. Suppression of actin polymerization may be an additional cause of low motility. ${ }^{32}$ Cell migration is strongly related to invasion and metastasis; thus, suppression of cell migration may contribute to prolonged survival time.

Our data indicate that $\mathrm{E} 3 \mathrm{C} 1$ treatment with nonviral vectors was effective for long periods in explanted tumors. The treatment attenuated cell adhesion and enhanced the sensitivity of the cells to deadhesion from matrix. It also suppressed phosphorylation of Akt, which has been regarded as a locus of drug resistance. ${ }^{33}$ Considering that cancer cells were supported by robust signaling networks for cell proliferation, cell migration, and multidrug resistance, induction of apoptosis via multiple pathways should be effective. ${ }^{34}$ From this perspective, $\mathrm{E} 3 \mathrm{C} 1$ which induces anoikis is candidate for a novel option in cancer therapy. Although treatment with E3C1 appears to be insufficiently effective to eradicate tumors, this biotherapeutic agent may overcome the low efficiency of nonviral vectors and tolerance to conventional therapy in combination with other chemotherapeutics. To develop E3C1 treatment into practical applications for improving the prognosis of cancer patients, its effects on other cell lines need to be examined. It has been reported that recombinant proteins with E3 domains induce apoptosis in COS-7 cells, a melanoma cell line, and a cell line derived from yolk sac, but not in murine erythroleukemia cells. ${ }^{20}$ As attenuation of cell adhesion is induced by $\mathrm{E} 3 \mathrm{C} 1$, treatment with $\mathrm{E} 3 \mathrm{C} 1$ would be ineffective against hematological malignancies, but useful against solid tumors.

\section{Acknowledgments}

This study was supported in part by a Grant-in-Aid for Scientific Research from the Ministry of Education and Culture of Japan. 


\section{Author contributions}

All authors contributed equally to ideas, data analysis, drafting and critically revising the paper, gave final approval of the version to be published, and agree to be accountable for all aspects of the work.

\section{Disclosure}

The authors report no conflicts of interest in this work.

\section{References}

1. Marshall E. Gene therapy death prompts review of adenovirus vector. Science. 1999;286(5448):2244-2245.

2. Gansbacher B. Report of a second serious adverse event in a clinical trial of gene therapy for X-linked severe combined immune deficiency (X-SCID). Position of the European Society of Gene Therapy (ESGT). J Gene Med. 2003;5(3):261-262.

3. Nayerossadat N, Maedeh T, Ali PA. Viral and nonviral delivery systems for gene delivery. Adv Biomed Res. 2012;1:27.

4. Zhang Y, Satterlee A, Huang L. In vivo gene delivery by nonviral vectors: overcoming hurdles? Mol Ther. 2012;20(7):1298-1304.

5. Fewell JG, Matar MM, Rice JS, et al. Treatment of disseminated ovarian cancer using nonviral interleukin-12 gene therapy delivered intraperitoneally. J Gene Med. 2009;11(8):718-728.

6. Sun X, Zhang HW, Zhang ZR. Growth inhibition of the pulmonary metastatic tumors by systemic delivery of the p27 kip 1 gene using lyophilized lipid-polycation-DNA complexes. J Gene Med. 2009;11(6): 535-544.

7. Klutz K, Willhauck MJ, Dohmen C, et al. Image-guided tumorselective radioiodine therapy of liver cancer after systemic nonviral delivery of the sodium iodide symporter gene. Hum Gene Ther. 2011; 22(12):1563-1574.

8. Alexander K, Hinds PW. Requirement for p27(KIP1) in retinoblastoma protein-mediated senescence. Mol Cell Biol. 2001;21(11): 3616-3631.

9. Schmitt CA, Fridman JS, Yang M, et al. A senescence program controlled by p53 and p16INK4a contributes to the outcome of cancer therapy. Cell. 2002;109(3):335-346.

10. Kitano H, Mamiya A, Hidai C. Improvement of FasL gene therapy in vitro by fusing the FasL to Dell protein domains. In: Yong P, Rijeka Y, editors. Targets in Gene Therapy. Croatia: InTech; 2011:147-158.

11. Kitano H, Mamiya A, Kokubun S, Hidai C. Efficient nonviral gene therapy with FasL and Del1 fragments in mice. J Gene Med. 2012;14(11): 642-650.

12. Hidai C, Zupancic T, Penta K, et al. Cloning and characterization of developmental endothelial locus-1: an embryonic endothelial cell protein that binds the alphavbeta3 integrin receptor. Genes Dev. 1998;12(1):21-33.

13. Kitano H, Hidai C, Kawana M, Kokubun S. An epidermal growth factorlike repeat of Del1 protein increases the efficiency of gene transfer in vitro. Mol Biotechnol. 2008;39(3):179-185.

14. Mamiya A, Kitano H, Takao K, Kokubun S, Komiya M, Hidai C. An epidermal growth factor motif from Dell protein increases the efficiency of in vivo gene transfer with a non-viral vector. Mol Biotechnol. 2013;54:445-450.

15. Hidai C, Kawana M, Kitano H, Kokubun S. Discoidin domain of Del1 protein contributes to its deposition in the extracellular matrix. Cell Tissue Res. 2007;330(1):83-95.
16. Urade M, Ogura T, Mima T, Matsuya T. Establishment of human squamous carcinoma cell lines highly and minimally sensitive to bleomycin and analysis of factors involved in the sensitivity. Cancer. 1992; 69(10):2589-2597.

17. Berger J, Hauber J, Hauber R, Geiger R, Cullen BR. Secreted placental alkaline phosphatase: a powerful new quantitative indicator of gene expression in eukaryotic cells. Gene. 1988;66(1):1-10.

18. Chin YR, Toker A. Function of Akt/PKB signaling to cell motility, invasion and the tumor stroma in cancer. Cell Signal. 2009;21(4): 470-476.

19. Radisavljevic Z. AKT as locus of cancer positive feedback loops and extreme robustness. J Cell Physiol. 2013;228(3):522-524.

20. Kitano H, Kokubun S, Hidai C. The extracellular matrix protein Del1 induces apoptosis via its epidermal growth factor motif. Biochem Biophys Res Commun. 2010;393(4):757-761.

21. Frisch SM, Francis H. Disruption of epithelial cell-matrix interactions induces apoptosis. J Cell Biol. 1994;124(4):619-626.

22. Penta K, Varner JA, Liaw L, Hidai C, Schatzman R, Quertermous T. Dell induces integrin signaling and angiogenesis by ligation of alphaVbeta3. J Biol Chem. 1999;274(16):11101-11109.

23. Choi EY, Chavakis E, Czabanka MA, et al. Del-1, an endogenous leukocyte-endothelial adhesion inhibitor, limits inflammatory cell recruitment. Science. 2008;322(5904):1101-1104.

24. Davies MA, Koul D, Dhesi H, et al. Regulation of Akt/PKB activity, cellular growth, and apoptosis in prostate carcinoma cells by MMAC/ PTEN. Cancer Res. 1999;59(11):2551-2556.

25. Bouchard V, Demers MJ, Thibodeau S, et al. Fak/Src signaling in human intestinal epithelial cell survival and anoikis: differentiation state-specific uncoupling with the PI3-K/Akt-1 and MEK/Erk pathways. J Cell Physiol. 2007;212(3):717-728.

26. Kapoor V, Zaharieva MM, Das SN, Berger MR. Erufosine simultaneously induces apoptosis and autophagy by modulating the Akt-mTOR signaling pathway in oral squamous cell carcinoma. Cancer Lett. 2012; 319(1):39-48.

27. van Blitterswijk WJ, Verheij M. Anticancer mechanisms and clinical application of alkylphospholipids. Biochim Biophys Acta. 2013;1831(3): 663-674.

28. Chan TO, Rittenhouse SE, Tsichlis PN. AKT/PKB and other D3 phosphoinositide-regulated kinases: kinase activation by phosphoinositide-dependent phosphorylation. Annu Rev Biochem. 1999;68:965-1014.

29. Kuo YC, Huang KY, Yang CH, Yang YS, Lee WY, Chiang CW. Regulation of phosphorylation of Thr-308 of Akt, cell proliferation, and survival by the B55alpha regulatory subunit targeting of the protein phosphatase 2A holoenzyme to Akt. J Biol Chem. 2008;283(4):1882-1892.

30. Vadlakonda L, Dash A, Pasupuleti M, Anil Kumar K, Reddanna P. The paradox of Akt-mTOR interactions. Front Oncol. 2013;3:165.

31. Antico Arciuch VG, Galli S, Franco MC, et al. Akt1 intramitochondrial cycling is a crucial step in the redox modulation of cell cycle progression. PLoS One. 2009;4(10):e7523.

32. Durham JT, Herman IM. Inhibition of angiogenesis in vitro: a central role for beta-actin dependent cytoskeletal remodeling. Microvasc Res. 2009;77(3):281-288.

33. Radisavljevic Z. AKT as locus of cancer multidrug resistance and fragility. J Cell Physiol. 2013;228(4):671-674.

34. Fiandalo MV, Kyprianou N. Caspase control: protagonists of cancer cell apoptosis. Exp Oncol. 2012;34(3):165-175. 


\section{Supplementary materials}

Control

\section{E3C1}

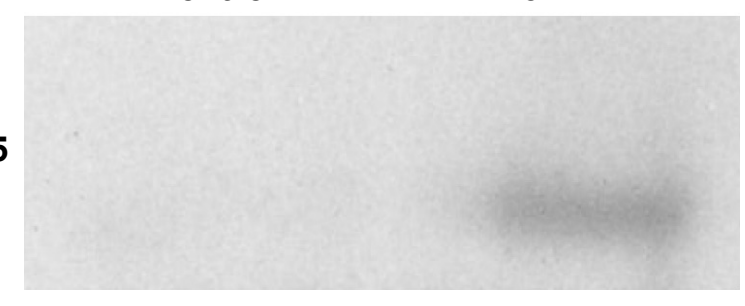

$\beta-A c t i n$

Figure SI Western blot of recombinant protein of $\mathrm{E} 3 \mathrm{CI}$.

Notes: $\mathrm{CHO}$ cells were cultured in a six-well dish, and were transfected with plasmids expressing pE3CI or pcDNA3 (negative control). After 4 hours, medium was replaced with I mL of 64 medium. After a further 96 hours, cells were fixed with I mL of $10 \%$ trichloroacetic acid and harvested with a cell scraper. Protein samples were separated by sodium dodecyl sulfate-polyacrylamide gel electrophoresis, and were transferred to a PVDF membrane (ATTO, Tokyo, Japan). The membrane was incubated with anti-V5 tag antibody (Invitrogen, Carlsbad, CA, USA), followed by a horseradish peroxidase-conjugated secondary antibody. $\beta$-Actin was used as a loading control.

Abbreviations: $\mathrm{CHO}$, Chinese Hamster Ovary; pE3CI, plasmid encoding E3CI; PVDF, polyvinylidene difluoride.
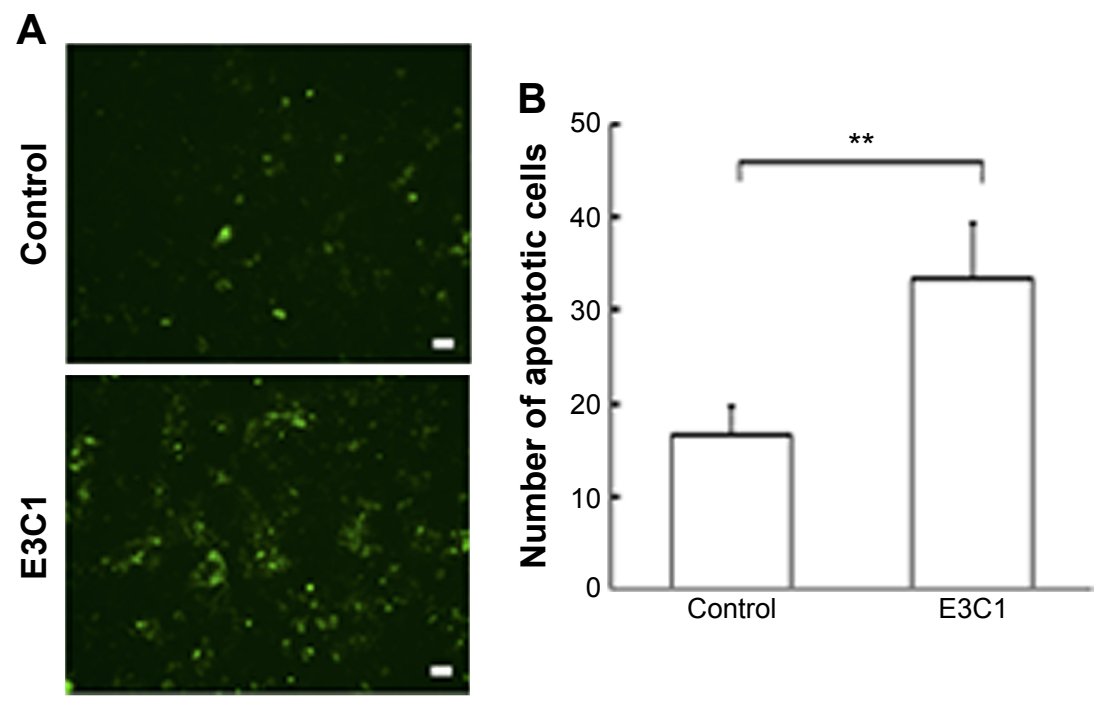

Figure S2 Repeated treatment with $\mathrm{E} 3 \mathrm{Cl}$ induced apoptosis in vitro.

Notes: (A) Apoptotic cells in control or E3CI-treated SCCKN cultured cells detected with polarity-sensitive indicator for viability and apoptosis-IANBD (Novus Biologicals, Littleton, CO, USA). Scale bars correspond to $50 \mu \mathrm{m}$. (B) The graph shows the number of apoptotic cells per field. Results are expressed as mean \pm standard deviation. $* * P<0.01$. 
Video SI Observation of migrating cells in 3D gel with mock treatment. A I20-minute movie was compressed to 10 seconds.

Video S2 Observation of migrating cells in 3D gel with E3CI treatment. A 120-minute movie was compressed to 10 seconds.

\section{Publish your work in this journal}

OncoTargets and Therapy is an international, peer-reviewed, open access journal focusing on the pathological basis of all cancers, potential targets for therapy and treatment protocols employed to improve the management of cancer patients. The journal also focuses on the impact of management programs and new therapeutic agents and protocols on

patient perspectives such as quality of life, adherence and satisfaction The manuscript management system is completely online and includes a very quick and fair peer-review system, which is all easy to use. Visit http://www.dovepress.com/testimonials.php to read real quotes from published authors.

Submit your manuscript here: http://www.dovepress.com/oncotargets-and-therapy-journal 